\title{
A Darriwilian (Middle Ordovician) bivalve-dominated molluscan fauna from the Stairway Sandstone, Amadeus Basin, central Australia
}

\author{
Kristian G. Jakobsen, Glenn A. Brock, Arne T. Nielsen, and David A. T. Harper \\ Acta Palaeontologica Polonica 61 (4), 2016: 897-924 doi:http://dx.doi.org/10.4202/app.00215.2015
}

A bivalve-dominated molluscan fauna is described from the Darriwilian (Middle Ordovician) Stairway Sandstone, Amadeus Basin, central Australia. The fauna comprises 16 species of bivalves and rostroconchs plus six gastropod species which are treated under open nomenclature. Two new bivalves, Sthenodonta paenesymmetrica sp. nov. and Modiolopsis pojetai sp. nov., are described. The relatively low-diverse molluscan fauna constitutes around $62 \%$ of the total benthic macrofauna. Approximately $75 \%$ of the molluscs comprise bivalves, especially nuculoids, which were biogeographically restricted to low latitudes during the Ordovician. The molluscan assemblage displays a very high degree of endemism at species level, though the bivalve Sthenodonta eastii also occurs in the Georgina Basin farther to the northeast. This indicates a possible marine connective seaway between the Georgina and Amadeus basins during the Darriwilian. Nuculites, Cyrtodonta, and Modiolopsis are cosmopolitan and previously reported from North China, Avalonia, and Southern Gondwana.

Key words: Mollusca, Bivalvia, endemicity, biodiversity, Ordovician, Darriwilian, Central Australia.

Kristian G. Jakobsen [krgj@ nanoq.gl], Geological Museum, Natural History

Museum of Denmark, University of Copenhagen, Øster Voldgade 5-7,

DK-1350 Copenhagen, Denmark; and Department of Biological Sciences,

Macquarie University, New South Wales 2109, Australia; current address:

Ministry of Mineral Resources, Government of Greenland, Imaneq 1A, 201,

GL-3900 Nuuk, Greenland. Glenn A. Brock [glenn.brock@mq.edu.au], Department of

Biological Sciences, Macquarie University, New South Wales 2109, Australia. Arne

T. Nielsen [arnet@snm.ku.dk], Geological Museum, Natural History

Museum of Denmark, University of Copenhagen, Øster Voldgade 5-7,

DK-1350 Copenhagen, Denmark. David A.T. Harper [david.harper@durham.ac.uk], Palaeoecosystems

Group, Department of Earth Sciences, Durham University, DH1 3LH Durham, UK. 
This is an open-access article distributed under the terms of the Creative Commons

Attribution License (for details please see creativecommons.org), which permits unrestricted use, distribution, and reproduction in any medium, provided the original author and source are credited.

Forif Full text $(2,874.3 \mathrm{kB})$ 